\title{
Mechanism Underlying Bonding Water Film Effect on Rheological Parameters
}

\author{
Yiyan Lv, ${ }^{1}$ Wei Zhu, ${ }^{1,2}$ and Tingting Han ${ }^{1}$ \\ ${ }^{1}$ Key Laboratory of Ministry of Education for Geomechanics and Embankment Engineering, Hohai University, Nanjing 210098, China \\ ${ }^{2}$ College of Environment, Hohai University, Nanjing 210098, China \\ Correspondence should be addressed to Wei Zhu; zhuweiteam.hhu@gmail.com
}

Received 6 April 2016; Revised 8 June 2016; Accepted 19 June 2016

Academic Editor: Philip Eisenlohr

Copyright (c) 2016 Yiyan Lv et al. This is an open access article distributed under the Creative Commons Attribution License, which permits unrestricted use, distribution, and reproduction in any medium, provided the original work is properly cited.

From experiments on bonding water of different slurries and the analysis of flow curves, the bilinear fluid model has been improved. The results showed that the rheological parameters correspond to physical processes at different stages of shear strain. As shear rate increases, slurries evolve from high-viscosity Bingham fluids to low-viscosity Bingham fluids. Specific surface area determines the number of edge-to-face arrangements; mineral composition influences the binding strength of each edge-to-face arrangement; and the volume fraction of particles regulates the distance between clay particles and number of edge-to-face arrangements.

\section{Introduction}

The rheological behavior of slurries has been the focus of attention in many engineering applications such as hydraulic dredging [1], well drilling [2], slurry shield tunneling [3], and paper industry [4]. The physical state of a clay may change with increasing water content: from a solid to a semirigid plastic, then to a gel, and finally to a suspension. Water in slurries is classified as being either adsorption water, capillary water, or free water depending on its distance from the surfaces of clay particles [5]. The rheological behavior of a clay-water system is determined by the forces that control the spatial arrangement and dynamics of clay particles with bonding water. These forces which mainly related to the particle hydration slow down the dynamics of water molecules within the force field of the clays. Thus, the forces increase the viscosity of slurry and modify its rheological behavior. But the effects of bonding water on the rheology of slurry are not yet well understood.

The non-Newtonian rheological characteristics of slurries depend on the particle size distribution [6] and the number and lifetime of the particle bindings [7] and are obviously related to volume fraction of particles in slurries [8]. A previous study pointed out that a slurry with more clay minerals has higher yield strength [9] because of the relationship between moisture and friction of the minerals [10]. Moreover, the thickness of bonding water films positively relates to cation exchange capacity (CEC) [11].

The Bingham model is usually used to describe slurries of high water content [12]. When water content decreases, slurries become fluids displaying power-law fluid with yield stress [13] and can be described by the Herschel-Bulkley model [14]. In ranges of lower shear stress, edge-to-face arrangement of clay mineral lamellae causes elasticity $[15,16]$. Viscoelastic behavior certainly occurs, but it liquefies in the upper stress range. So some researchers believe slurry can be described by a complex model combining the Bingham model at low strain rate and the Herschel-Bulkley model at high strain rate [17]. Also, it can be described by a bilinear fluid model combining the description of a pseudo-Newtonian fluid at low strain rate and a Bingham fluid at high strain rate [18-20]. Actually, slurries under shearing produce a fast layer that transfers momentum to an adjoining layer of slower speed, with the value of yield stress reflecting the rate of flux of momentum [7]. However, the variation of microcell resisting shear force with macroscopic model parameters is still unclear.

This study on slurries improves the bilinear fluid model providing a better fit to actual flow curves and better analysis of effects of specific surface area (SSA), mineral composition, and volume fraction of particles $\left(\phi_{c}\right)$ on rheological properties. The correspondence between rheological parameters 

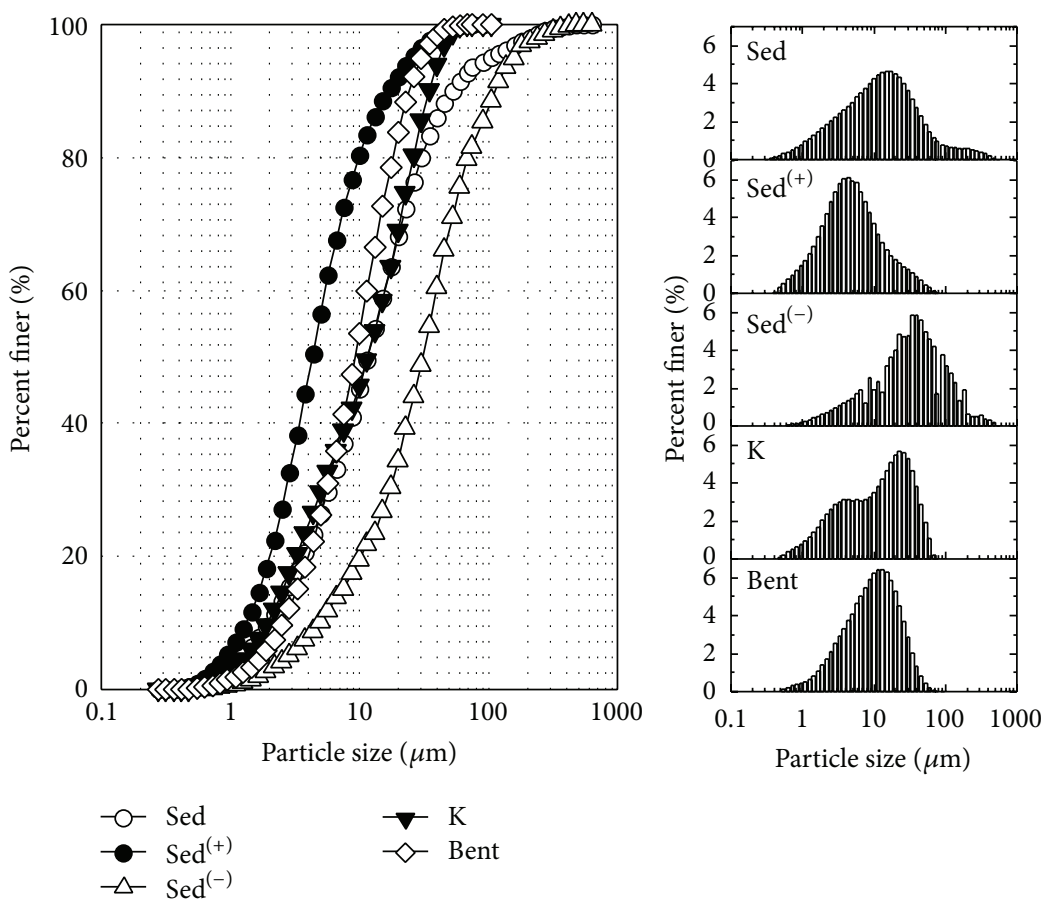

Figure 1: Particle size distribution curve of slurries.

TABLE 1: Physical properties of slurries.

\begin{tabular}{|c|c|c|c|c|c|c|}
\hline Slurry type & Specific gravity & Liquid limit (\%) & Plastic limit (\%) & Clay fractions ${ }^{\mathrm{a}}(\%)$ & $\operatorname{SSA}\left(\mathrm{m}^{2} / \mathrm{g}\right)$ & $\mathrm{CEC}(\mathrm{mEq} / 100 \mathrm{~g})$ \\
\hline Sed & 2.68 & 56 & $29 \%$ & $26.3 \%$ & 37.2 & 41.3 \\
\hline $\operatorname{Sed}^{(+)}$ & 2.68 & 68 & $37 \%$ & $56.4 \%$ & 79.5 & 89.1 \\
\hline $\operatorname{Sed}^{(-)}$ & 2.68 & 47 & $24 \%$ & $15.2 \%$ & 17.4 & 18.3 \\
\hline K & 2.65 & 39 & $23 \%$ & $29.7 \%$ & 31.9 & 6.7 \\
\hline Bent & 2.75 & 162 & $51 \%$ & $26.2 \%$ & 552.7 & 93.4 \\
\hline
\end{tabular}

$\mathrm{a}_{<5} \mu \mathrm{m}$.

and microscopic physical processes when slurries undergo shearing is also discussed.

\section{Materials and Methods}

2.1. Preparation of Slurries. Five groups of slurries were used in experiments: original sediment (Group Sed, from Taihu Lake, Jiangsu province, China), sediment with added clay fractions (Group Sed ${ }^{(+)}$), sediment with reduced clay fractions (Group Sed ${ }^{(-)}$), kaolin with distilled water (Group K, from Hebei province, China), and bentonite with distilled water (Group Bent, from Jiangsu province, China). The $4.5 \%$ organic matter in Group Sed was extracted using $\mathrm{H}_{2} \mathrm{O}_{2}$ in pretreatment, and Group Sed was divided into Group Sed ${ }^{(+)}$ and Group Sed ${ }^{(-)}$using the hydrostatic settlement method. The particle size distribution for each group was measured with Mastersizer 2000 laser particle characterization system (Malvern Instruments Ltd., Malvern, UK) using pure ethyl alcohol as dispersion medium. Distribution results for Group Sed, Group K, and Group Bent were similar when particle size is less than $10 \mu \mathrm{m}$ (Figure 1). The physical properties of clay
TABLE 2: Mineral composition analysis.

\begin{tabular}{lcccc}
\hline Slurry type & Illite & Kaolin & Montmorillonite & Quartz \\
\hline Sed & $61.4 \%$ & $13.2 \%$ & $4.8 \%$ & $20.6 \%$ \\
K & $2.5 \%$ & $90.1 \%$ & $1.2 \%$ & $6.2 \%$ \\
Bent & $2.8 \%$ & $1.7 \%$ & $95.3 \%$ & $0.2 \%$ \\
\hline
\end{tabular}

particles in slurries are listed in Table 1. Results of analysis for the mineral composition from X-ray diffractometry are listed in Table 2.

2.2. Instrumentation and Methods. The measurements of the flow curves of the slurry groups were obtained by using a rotational rheometer (NXS-11B, Chengdu Instrument Factory, Chengdu, China) which was equipped with a concentric cylinder geometry [21]. The rheometer has 5 test systems for testing various slurries (Table 3 ) and 15 grades of rotation speed in the range of $5.6 \sim 360 \mathrm{r} / \mathrm{min}$. The measuring ranges of the rheometer and shear stress are $2.8 \sim 1.78 \times 10^{7} \mathrm{mPa} \cdot \mathrm{s}$ and $27.67 \sim 21,970 \mathrm{~Pa}$, respectively. The rheometer has 5 test 

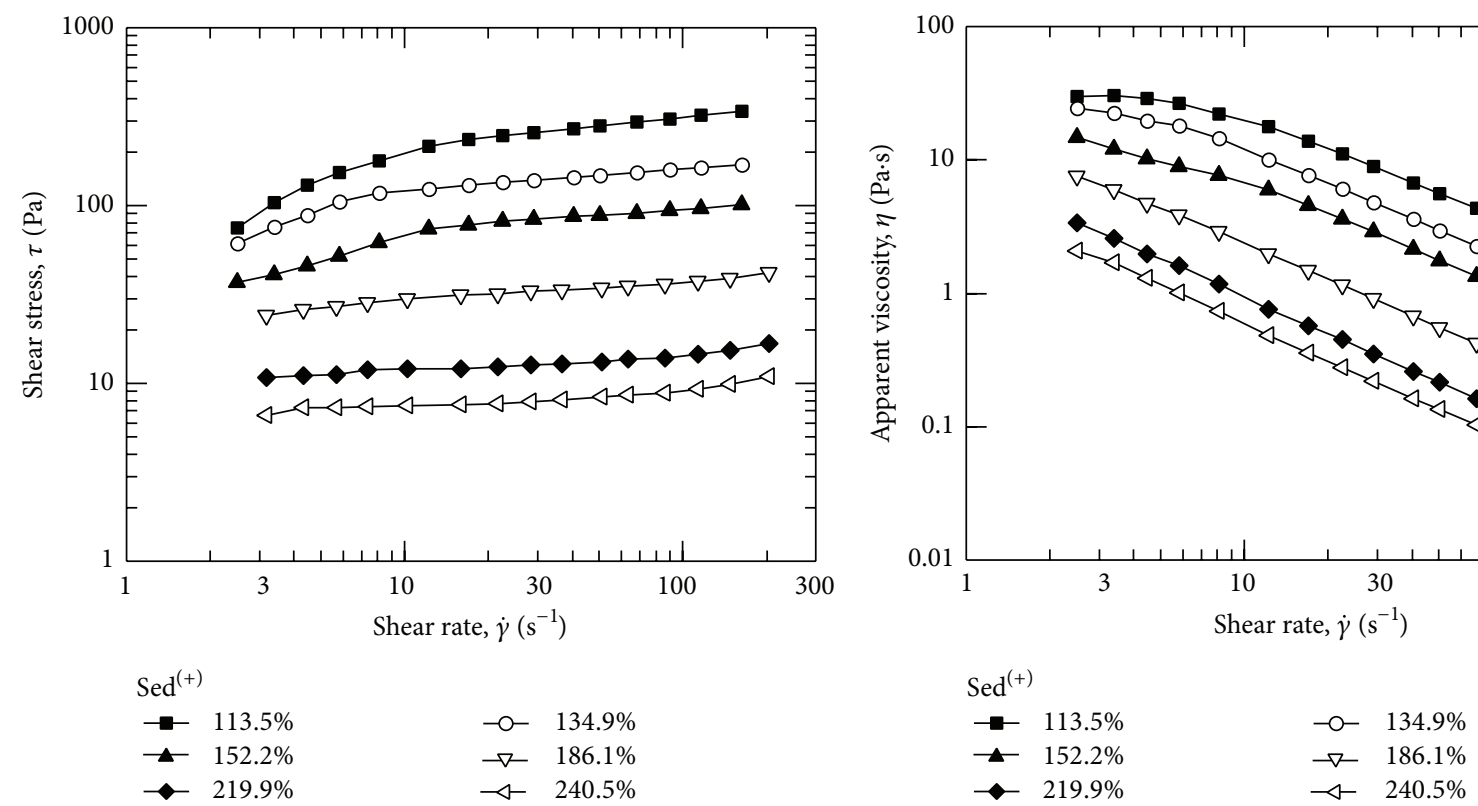

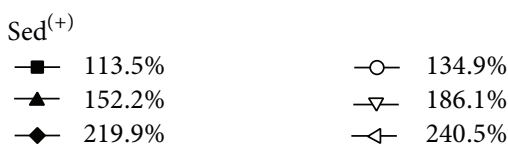

(a)

(b)

FIgURE 2: The variation of typical flow curves with water content. (a) Plot of log shear stress versus log shear rate. (b) Plot of log apparent viscosity versus $\log$ shear rate.

TABLE 3: Test systems of NXS-11B type rotational rheometer.

\begin{tabular}{lccccc}
\hline Test system & A & B & C & D & E \\
\hline Diameter of inner bob $(\mathrm{cm})$ & 4 & 4 & 2 & 2 & 2 \\
Diameter of outer cup $(\mathrm{cm})$ & 3.846 & 3.177 & 1.460 & 0.862 & 0.432 \\
Height of inner bob $(\mathrm{cm})$ & 7 & 5 & 3 & 1.5 & 0.7 \\
Specimen volume $(\mathrm{mL})$ & 20 & 60 & 9 & 10 & 12 \\
\hline
\end{tabular}

systems for testing various slurries (Table 3). All the measurements were carried out at a constant temperature of $25^{\circ} \mathrm{C}$.

To measure the adsorption water content, the following procedure was used: add some dry clay powders with mass $m_{s}$ into a volumetric flask with enough distilled water. When the clay reaches adsorption saturation, the water volume would shrink $\Delta V$. The mass ratio of absorption water and dry clay can be calculated from

$$
w_{b}=\frac{\Delta V \rho_{b} \rho_{f}}{m_{s}\left(\rho_{b}-\rho_{f}\right)},
$$

with the density of distilled water being $\rho_{f}=1.0 \mathrm{~g} / \mathrm{m}^{3}$. The average density of adsorption water in typical clay is $\rho_{b}=$ $1.4 \mathrm{~g} / \mathrm{m}^{3}[22]$.

\section{Results}

3.1. Rheological Behaviors of Slurries. The flow curves of five groups of slurries are obtained through the controlled shear rate test. Take Group Sed ${ }^{(+)}$as an example; typical curves plotted in a log-log scale are shown in Figure 2. The results showed that all flow curves of the slurries had a similar

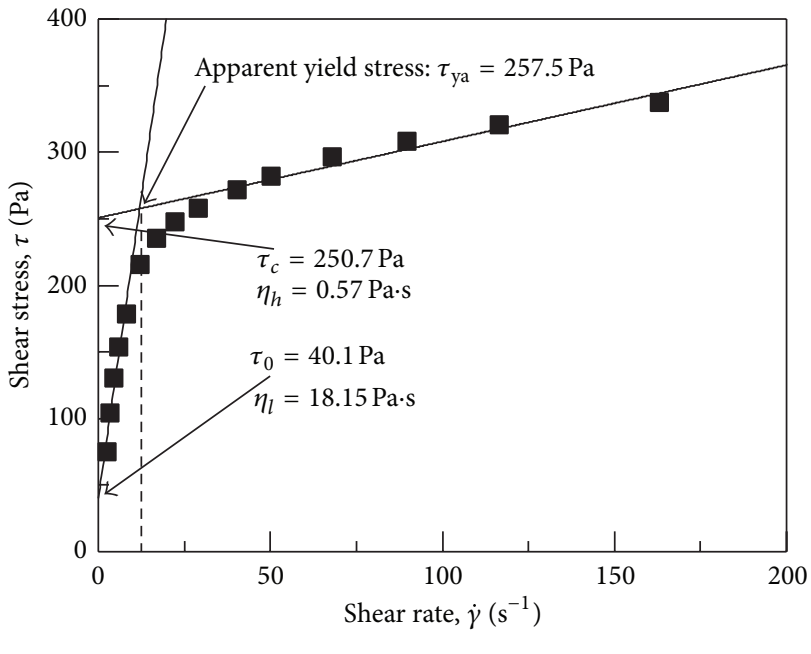

- Sed $^{(+)}{ }_{-113.5 \%}$

FIGURE 3: Determination of dynamic yield stress, Bingham yield stress, plastic viscosity of low shear rate region, and plastic viscosity of high shear rate region for the Group Sed ${ }^{(+)}$sample at a water content of $113.5 \%$.

tendency that at high water content they were close to indicating ideal Bingham fluids; and at low water content, the flow curves exhibit both pseudoplastic (shear-thinning) and viscoplastic (presence of a yield stress) behavior.

Values for the rheological parameters are deduced from the flow curves. To illustrate, we take the data for Group Sed $^{(+)}$at water content of $113.5 \%$ as an example (Figure 3 ). 


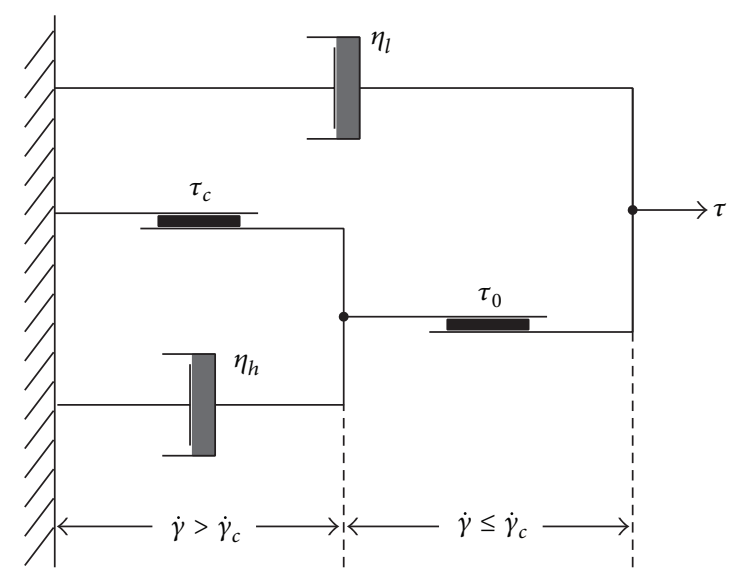

FIGURE 4: Schematic diagram of improved bilinear fluid model.

To describe precisely the physical meaning of the rheological parameters, the bilinear fluid model was improved as follows:

$$
\tau=\left\{\begin{array}{cc}
\tau_{0}+\eta_{l} \dot{\gamma} & \left(\dot{\gamma} \leq \dot{\gamma}_{c}\right) \\
\tau_{c}+\eta_{h} \dot{\gamma} & \left(\dot{\gamma}>\dot{\gamma}_{c}\right)
\end{array}\right\} .
$$

There are some rheological parameters: $\tau_{0}$ is the dynamic yield stress, which is explained as the extrapolated stress from the low shear rate region. At stresses below this yield stress, the slurry behaves like a solid. $\tau_{c}$ is the intersection of the linear part of high shear rate region on the rheogram and the vertical coordinates (as shown in Figure 3), which can be called the Bingham yield stress [19]. $\eta_{l}$ and $\eta_{h}$ are the plastic viscosities (PV) which correspond to the gradient of the linear part of the rheogram in low shear rate region and low shear rate region, respectively. $\dot{\gamma}_{c}$ is the shear rate in the transition region (at this shear rate $\tau=\tau_{\text {ya }}$, which can be defined as the apparent yield stress [19]). Usually, $\tau_{\text {ya }}$ is a little higher than $\tau_{c}$ on the rheogram. For convenience sake, $\tau_{\mathrm{ya}}$ is approximately equal to $\tau_{c}$.

Viscoplasticity material can be described by an appropriate mathematical model, and the basic components used to describe the viscoplastic properties are friction elements and Newton sticky pots. According to the proposed model in (2), a mechanical model is represented schematically in Figure 4. The model consists of two friction elements and two Newton sticky pots. At stresses below the dynamic yield stress, the friction element $\tau_{0}$ remains rigid and $\dot{\gamma}=0 \mathrm{~s}^{-1}$. As soon as the strain energy exceeds the level required by the von Mises criterion [23], the elastic stress in the friction element attains the yield value and the friction element $\tau_{0}$ breaks allowing deformation of Newton sticky pot $\eta_{l}$. Consequently, the slurry predicts a Bingham fluid behavior of high viscosity at low shear rate $\left(0<\dot{\gamma} \leq \dot{\gamma}_{c}\right)$. As the shear rate exceeds $\dot{\gamma}_{c}$, the friction element $\tau_{c}$ breaks and the whole system predicts a Bingham fluid behavior of low viscosity at high shear rate $\left(\dot{\gamma}>\dot{\gamma}_{c}\right)$ due to the Newton sticky pot $\eta_{h}$.

In general, as water content decreased, all flow curves of slurries evolved along a pathway describing a Newton fluid, a Bingham fluid, and then a power-law fluid with yield

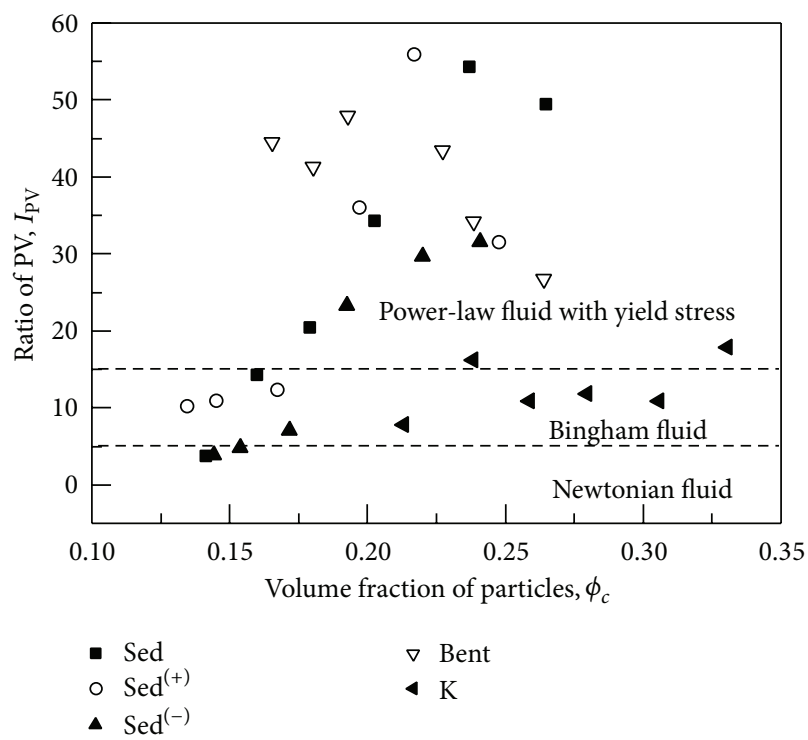

FIGURE 5: Sectioning of fluid type by the ratio of plastic viscosities in the improved bilinear fluid model.

TABLE 4: Adsorption water-dry clay mass ratio.

\begin{tabular}{lc}
\hline Slurry type & Bound water-dry clay mass ratio \\
\hline Sed & 0.1156 \\
Sed $^{(+)}$ & 0.2565 \\
Sed $^{(-)}$ & 0.0513 \\
K & 0.0132 \\
Bent & 0.2143 \\
\hline
\end{tabular}

stress. This trend could be described using a ratio of plastic viscosities (PV):

$$
I_{\mathrm{PV}}=\frac{\eta_{l}}{\eta_{h}}
$$

To evaluate the shear-thinning behavior, the relationship between $I_{\mathrm{PV}}$ and $\phi_{c}$ is plotted in Figure 5. If $I_{\mathrm{PV}}=5$ and $I_{\mathrm{PV}}=$ 15 are taken as the lower and upper limits, respectively, for Bingham fluids, the $I_{\mathrm{PV}}$ distribution for Group Sed, Group $\operatorname{Sed}^{(+)}$, and Group Sed ${ }^{(-)}$evolves along the same pathway with increasing $\phi_{c}$. However, the $I_{\mathrm{PV}}$ distribution of Group Bent retains the character of a power-law fluid with yield stress, whereas Group K retains Bingham fluid characteristics even at high $\phi_{c}$.

3.2. Adsorption Water Content. The adsorption water-dry clay mass ratio $w_{b}$ of all groups is listed in Table 4. Obviously, slurry groups with high value of SSA and CEC have larger $w_{b}$.

\section{Discussion}

4.1. Relationship between SSA and Rheological Behaviors. In comparing Group Sed, Group Sed ${ }^{(+)}$, and Group Sed ${ }^{(-)}$, which are of similar mineral composition but different SSA, their bilinear rheological parameters were found to be entirely different (Figure 6). 

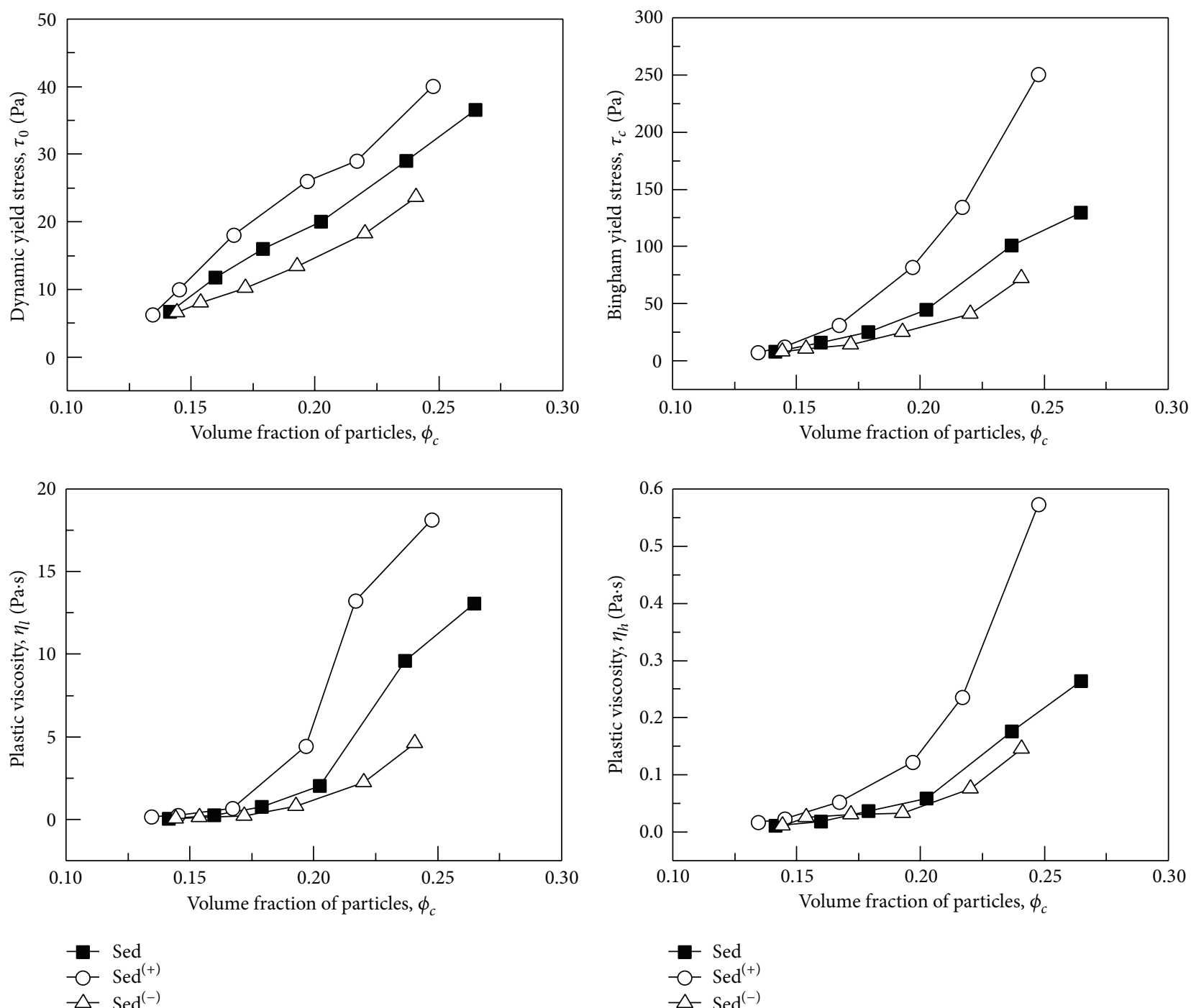

FIGURE 6: Bilinear rheological parameters of Group Sed, Group Sed ${ }^{(+)}$, and Group Sed ${ }^{(-)}$.

Supposing the adsorption water was evenly distributed over the clay particle surface, the thickness of the adsorption water film $\delta_{b}$ is then obtained from

$$
\delta_{b}=\frac{w_{b} m_{s}}{\rho_{b} m_{s} \mathrm{SSA}}=\frac{w_{b}}{\rho_{b} \mathrm{SSA}} .
$$

With the existing data, the thickness ratio of the adsorption water film for each of the three groups is $\delta_{b}(\mathrm{Sed}): \delta_{b}\left(\operatorname{Sed}^{(+)}\right): \delta_{b}\left(\operatorname{Sed}^{(-)}\right)=1: 1.04: 0.95$. This implies that the same mineral composition leads to the same charge density on the particle surface and consequently the same thickness of bonding water, irrespective of SSA. Therefore, the bonding strength of every edge-to-face arrangement was almost the same in slurries at similar $\phi_{c}$. Nevertheless, slurries with higher SSA had more edge-to-face arrangements, leading to differences in macroscopic rheological parameters among the groups. Moreover, all $\tau_{0}$ and $\tau_{c}$, as well as all $\eta_{l}$ and $\eta_{h}$, were close when $\phi_{c}=0.15$. That implies that slurry viscosity derives mainly from hydration forces from capillary water because of greater distances between particles and less edge-to-face arrangements. In this situation, SSA had little influence on rheological behavior. However, such an influence would be more obvious if $\phi_{c}$ increased.

4.2. Relationship between Mineral Composition and Rheological Behavior. Comparing Group Sed, Group K, and Group Bent, which have very similar particle size distributions but different mineral compositions, their bilinear rheological parameters were also found to be entirely different (Figure 7).

The thickness ratio of the adsorption water for each of three groups is $\delta_{\mathrm{bw}}(\mathrm{Sed}): \delta_{\mathrm{bw}}(\mathrm{K}): \delta_{\mathrm{bw}}(\mathrm{Bent})=1: 0.13: 2$. The specific surface area can be very large. The primary surface area of montmorillonite, that is, the surface area exclusive of interlayer zones, ranges from 50 to $120 \mathrm{~m}^{2} / \mathrm{g}$ [24]. Thus, the SSA for Group Bent was weighted by a hypothetic factor $1 / 16$ to account for the large difference between internal and external surface areas. The same particle size distribution implies an equal number of edge-to-face arrangements, 

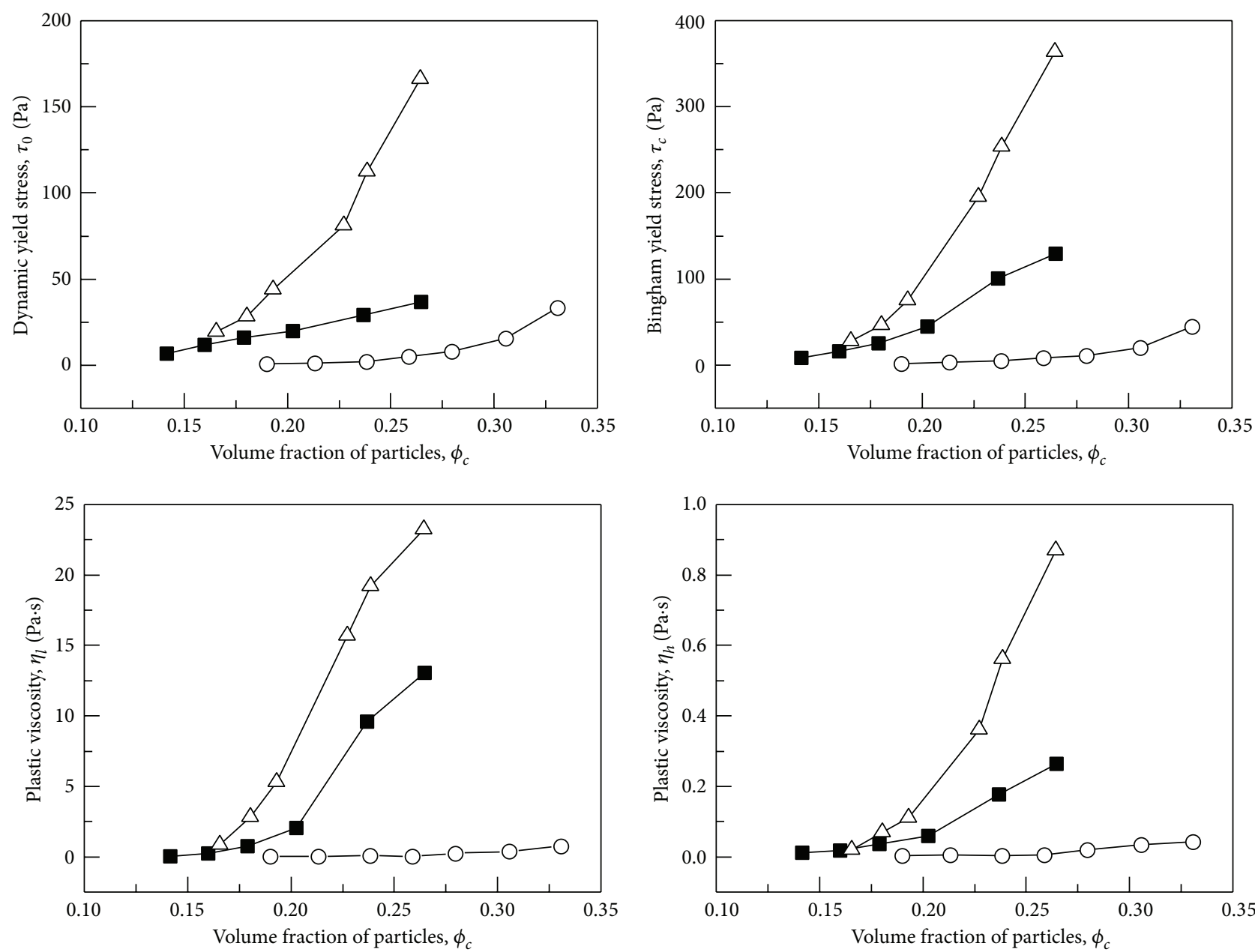

- Sed

$-\mathrm{O}-\mathrm{K}$

$\triangle$ Bent

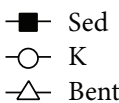

FIGURE 7: Bilinear rheological parameters for Group Sed, Group K, and Group Bent.

whereas thickness differences in adsorption water reflected differences in charge density over the mineral surfaces. The surface charge density is obtained from

$$
\sigma=\frac{\mathrm{CEC}}{\mathrm{SSA}} F,
$$

where $F$ is Faraday's constant, $\mathrm{C} / \mathrm{mol}$.

The charge density was positively related to CEC, and the fractional ratio for the three groups of $\sigma(\mathrm{Sed}): \sigma(\mathrm{K}): \sigma(\mathrm{Bent})=1: 0.18: 2.43$ was close to the thickness ratio of adsorption water film. With higher charge density, the particle can adsorb more hydration cations. This leads to thicker bonding water films and higher bonding strength in edge-to-face arrangements. Therefore, surface charge density had a decisive influence on rheological parameters. However, for slurries at low $\phi_{c}$, the rheological parameters were similar in value as described earlier.
4.3. Internal Mechanism of Rheological Behaviors. The rheological properties of clay minerals depend on the particle structure. The clay mineral lamellae generally carry negative charges on their faces and positive charges on their edges [25]; thus the card-houses structure can be formed. The edge-toface arrangements are the major binding elements in claywater systems (Figure 8). The high viscosities are due to the existence of flocs which contain immobilized suspending fluids in their structures, and the effective particle volume fraction is increased. When slurries undergo shearing, the impulse is passed from fast to slow flocs due to differences in speed between adjacent layers. In this process, there are three stages depending on shear rate.

Stage I. If shear rate is extremely low, the shear force imparted is less than the bonding strength of the edge-to-face arrangements. The floc would not distort and the macroscopic shear strength equaled the dynamic yield stress $\tau_{0}$. This indicated 

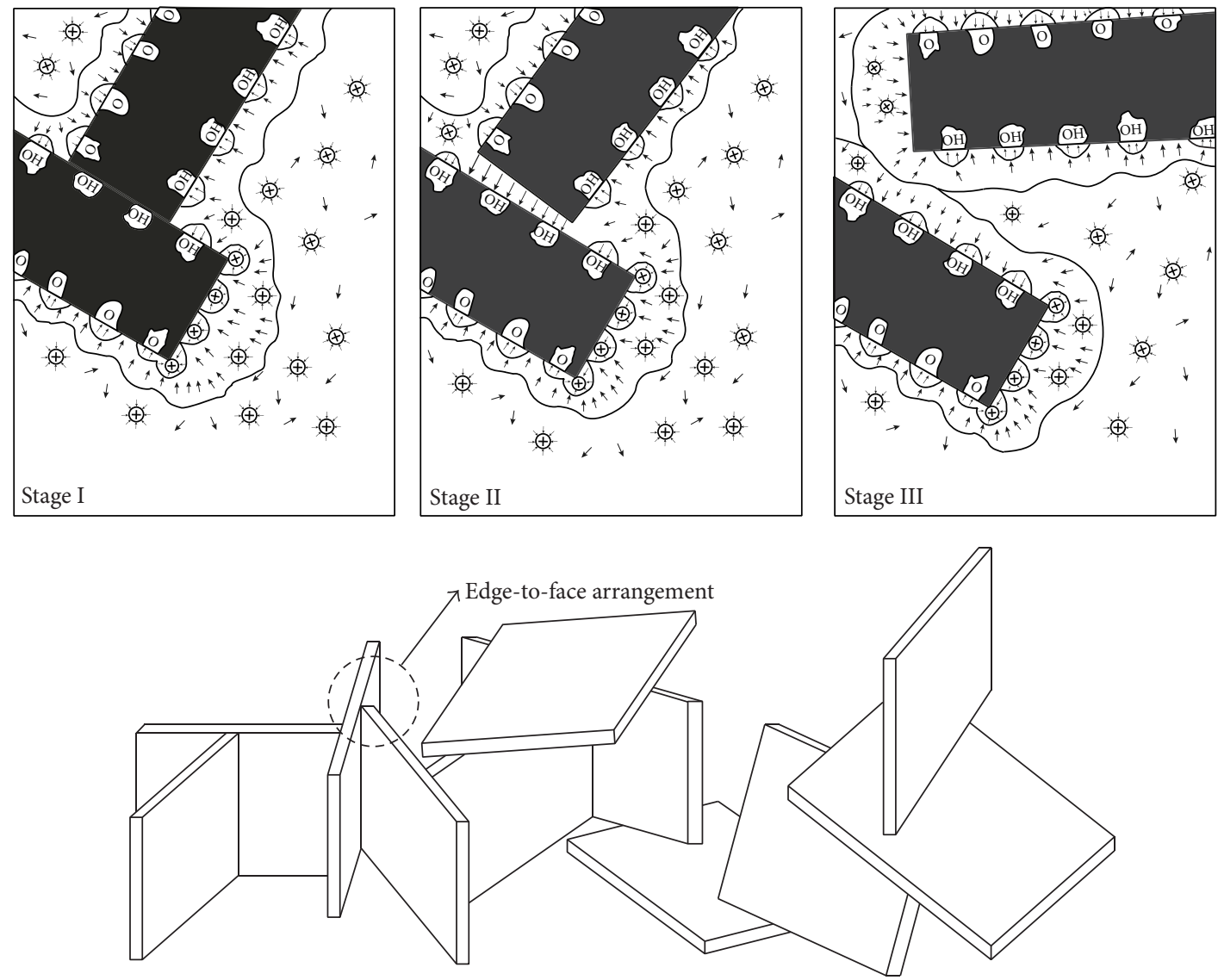

FIGURE 8: Various stages of edge-to-face arrangements under shearing.

that the slurries possessed a very strong solid-like behavior rather than a liquid-like behavior.

Stage II. If the shear rate is low and less than $\dot{\gamma}_{c}$, the shear stress is greater than $\tau_{0}$. The floc begins to distort, and a short distance appeared in the edge-to-face arrangement. However, the particles are still subjected to surface charge attraction. The internal friction of slurries mainly comes from hydration of the adsorption water, leading to a higher viscous coefficient $\eta_{l}$. Once the shear rate reaches $\dot{\gamma}_{c}$, the effect of adsorption water maximizes and subsequently the macroscopic shear strength equals $\tau_{c}$.

Stage III. If the shear rate exceeds $\dot{\gamma}_{c}$, the effect of adsorption water gradually weakens. The internal friction of slurries mainly stems from hydration of the capillary water, leading to a lower coefficient of viscosity $\eta_{h}$.

Moreover, shear rate and volume fraction of particles are primarily important, because these rheological parameters reflect not only the strength of edge-to-face arrangements but also the number of such arrangements. In slurries with low $\phi_{c}$, large separations between flocs led to less efficient edgeto-face arrangements. As a result, all macroscopic rheological parameters are low in value.

\section{Conclusions}

The improved bilinear fluid model describes more precisely the rheological curves of slurries. If the shear rate is around zero, the edge-to-face arrangement mainly produces binding forces among particles which then is seen as a dynamic yield stress $\tau_{0}$ at the macroscopic scale. The separation in edge-to-face arrangements is stretched with increasing shear rate, and slurries appear as Bingham fluids characterized by high coefficients of viscosity $\eta_{l}$ as a consequence of hydration of high-density adsorption water. Once the shear rate exceeds $\dot{\gamma}_{c}$, the separation in edge-to-face arrangements weakens binding from adsorption water. Capillary water and free water dictate the behavior of slurries which appear as Bingham fluids characterized by yield point $\tau_{c}$ and low coefficient of viscosity $\eta_{h}$.

Slurry groups of the same mineral composition but different SSA had different rheological parameters. The primary reason is the difference in number of edge-to-face arrangements, although the thickness of bonding water and the binding strength of each arrangement were similar. Slurry groups with the same SSA but different mineral compositions had different rheological parameters. This is because the surface charge densities of different minerals are not equal, leading to difference in binding strength of edge-to-face 
arrangements. Clay minerals with higher surface charge densities have thicker bonding water films. Volume fraction of particles can affect the spacing between particles and the number of edge-to-face arrangements. If $\phi_{c}<0.15$, the effect of hydration on particles could be ignored; thus the rheological parameters of all slurry groups were close.

\section{Competing Interests}

The authors declare that they have no competing interests.

\section{Acknowledgments}

The authors would like to thank the National Basic Research Program of China (“973” Program, no. 2012CB719804) and Nurturing Project of National Engineering Research Center for Dredging and Mud Treatment (Jiangsu province, China, no. BM2013013) for supporting this research.

\section{References}

[1] M. Chowdhury and F. Testik, "Subaqueous cohesive sediment gravity flows from open water pipeline dredge disposal: laboratory experiments and mathematical modeling," in Coastal Engineering Practice, pp. 460-472, 2011.

[2] M. Mohammadi, M. Kouhi, A. Sarrafi, and M. Schaffie, "Studying rheological behavior of nanoclay as oil well drilling fluid," Research on Chemical Intermediates, vol. 41, no. 5, pp. 2823-2831, 2015.

[3] F. Min, W. Zhu, and X. Han, "Filter cake formation for slurry shield tunneling in highly permeable sand," Tunnelling and Underground Space Technology, vol. 38, pp. 423-430, 2013.

[4] W. M. Bundy and J. N. Ishley, "Kaolin in paper filling and coating," Applied Clay Science, vol. 5, no. 5-6, pp. 397-420, 1991.

[5] T. Saarenketo, "Electrical properties of water in clay and silty soils," Journal of Applied Geophysics, vol. 40, no. 1-3, pp. 73-88, 1998.

[6] C. Zanelli, C. Iglesias, E. Domínguez et al., "Mineralogical composition and particle size distribution as a key to understand the technological properties of Ukrainian ball clays," Applied Clay Science, vol. 108, pp. 102-110, 2015.

[7] T. Gillespie, "An extension of Goodeve's impulse theory of viscosity to pseudoplastic systems," Journal of Colloid Science, vol. 15, no. 3, pp. 219-231, 1960.

[8] J. L. Amorós, V. Beltrán, V. Sanz, and J. C. Jarque, "Electrokinetic and rheological properties of highly concentrated kaolin dispersions: influence of particle volume fraction and dispersant concentration," Applied Clay Science, vol. 49, no. 1-2, pp. 33-43, 2010.

[9] S. P. Bentley, "Viscometric assessment of remoulded sensitive clays," Canadian Geotechnical Journal, vol. 16, no. 2, pp. 414-419, 1979.

[10] C. A. Morrow, D. E. Moore, and D. A. Lockner, "The effect of mineral bond strength and adsorbed water on fault gouge frictional strength," Geophysical Research Letters, vol. 27, no. 6, pp. 815-818, 2000.

[11] K. Tone, M. Kamori, Y. Shibasaki, Y. Takeda, and O. Yamamoto, "Effect of the surface potential on the cation exchange capacity of kaolin minerals," Clay Science, vol. 10, pp. 327-335, 1998.
[12] J. Locat and D. Demers, "Viscosity, yield stress, remolded strength, and liquidity index relationships for sensitive clays," Canadian Geotechnical Journal, vol. 25, no. 4, pp. 799-806, 1988.

[13] T. Hemphil, W. Campos, and A. Pilehvari, "Yield-power law model more accurately predicts mud rheology," Oil \& Gas Journal, vol. 91, no. 34, pp. 45-50, 1993.

[14] H. A. Barnes, "The yield stress-a review or 'panta roi'-everything flows?" Journal of Non-Newtonian Fluid Mechanics, vol. 81, no. 1-2, pp. 133-178, 1999.

[15] E. Tombácz and M. Szekeres, "Colloidal behavior of aqueous montmorillonite suspensions: the specific role of $\mathrm{pH}$ in the presence of indifferent electrolytes," Applied Clay Science, vol. 27, no. 1-2, pp. 75-94, 2004.

[16] E. Tombácz and M. Szekeres, "Surface charge heterogeneity of kaolinite in aqueous suspension in comparison with montmorillonite," Applied Clay Science, vol. 34, no. 1-4, pp. 105-124, 2006.

[17] T. Inoue, T.-S. Tan, and S.-L. Lee, "An investigation of shear strength of slurry clay," Soils and Foundations, vol. 30, no. 4, pp. $1-10,1990$.

[18] S. W. Jeong, "The viscosity of fine-grained sediments: a comparison of low- to medium-activity and high-activity clays," Engineering Geology, vol. 154, pp. 1-5, 2013.

[19] S. W. Jeong, J. Locat, S. Leroueil, and J.-P. Malet, "Rheological properties of fine-grained sediment: the roles of texture and mineralogy," Canadian Geotechnical Journal, vol. 47, no. 10, pp. 1085-1100, 2010.

[20] J. Locat, "Normalized rheological behaviour of fine muds and their flow properties in a pseudoplastic regime," in Proceedings of 1st International Conference on Debris-Flow Hazards Mitigation: Mechanics, Prediction, and Assessment, pp. 260-269, ASCE, San Francisco, Calif, USA, 1997.

[21] M. Cao, Q. Yan, X. Li, and Y. Mi, "Effect of plate-like alumina on the properties of alumina ceramics prepared by gel-casting," Materials Science and Engineering: A, vol. 589, pp. 97-100, 2014.

[22] H. Yao, P. Cheng, Y. Yang, and W. Wu, “Theory and practice concerning classification for expansive soils using standard moisture absorption water content," Science in China, Series E: Technological Sciences, vol. 48, no. 1, pp. 31-40, 2005.

[23] P. Saramito, "A new elastoviscoplastic model based on the Herschel-Bulkley viscoplastic model," Journal of Non-Newtonian Fluid Mechanics, vol. 158, no. 1-3, pp. 154-161, 2009.

[24] J. K. Mitchell and K. Soga, Fundamentals of Soil Behavior, 2005.

[25] H. Yilmaz, S. Güler, and Ç. Güler, "The rheological and dielectric properties of kaolinite suspensions in the presence of alcohols," Physica Scripta, vol. 59, no. 1, pp. 77-80, 1999. 

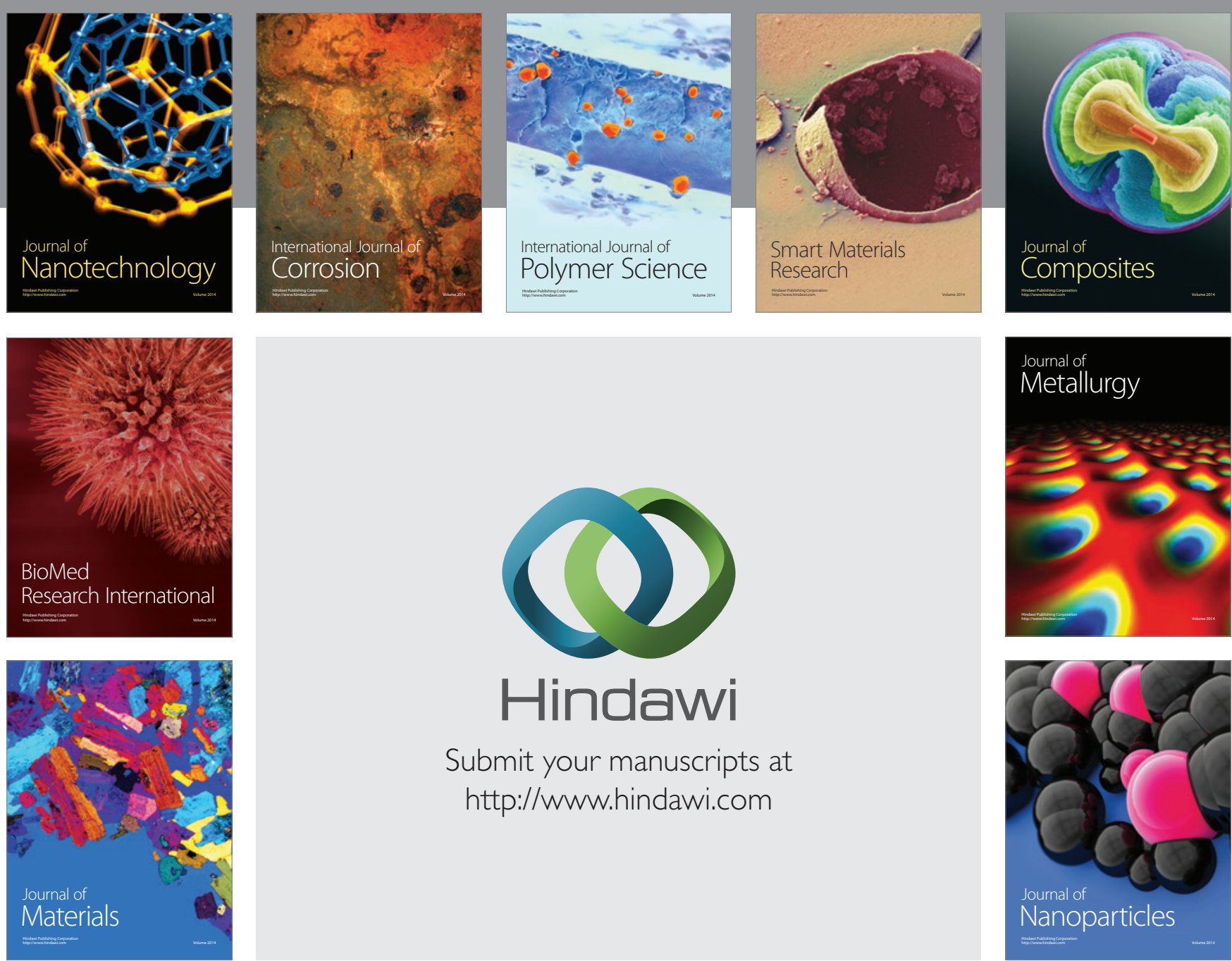

\section{Hindawi}

Submit your manuscripts at

http://www.hindawi.com

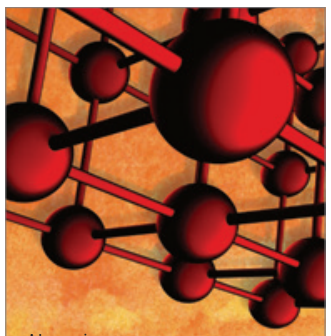

Materials Science and Engineering
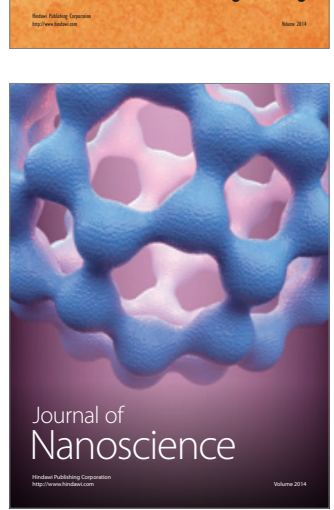
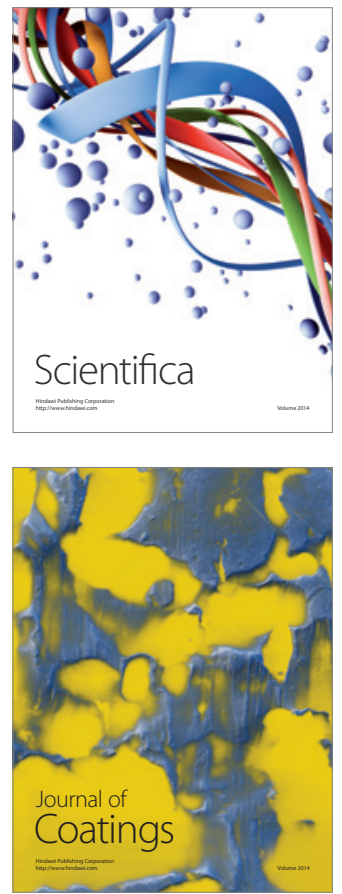
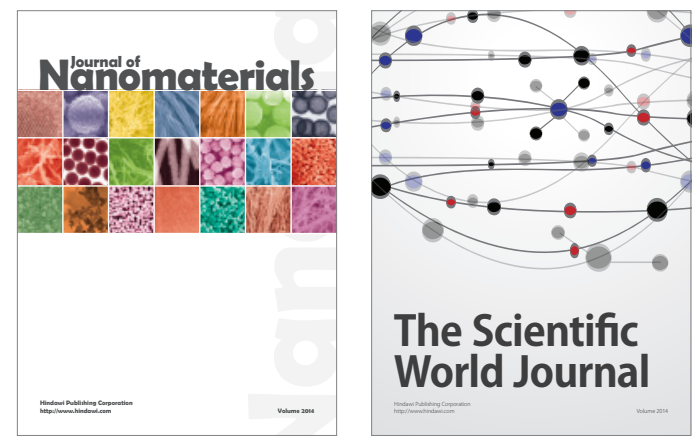

The Scientific World Journal
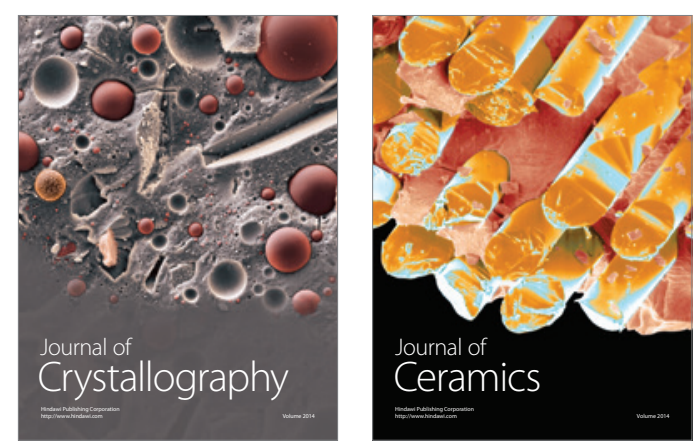
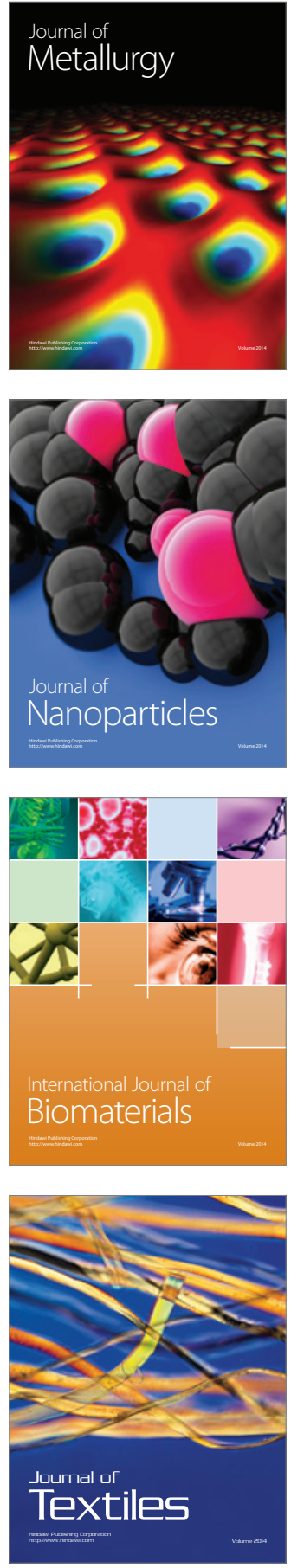